\title{
Is erosion by deforming subglacial sediments significant? (Toward till continuity)
}

\author{
Kurt Cuffey \\ Department of Geological Sciences, Box 351310, University of Washington, Seattle, WA 98195, U.S.A. \\ Richard B. Alley \\ Department of Geosciences and Earth System Science Center. The Pennsylvania State University, University Park, PA 16802, U.S.A.
}

\begin{abstract}
A glacier moving by deformation of subglacial sediments will tend to exhaust its own sediment supply, unless new sediment is generated subglacially. We explore the potential for deforming sediments to overcome this difficulty and replenish themselves by abrading their beds. We review abrasion experiments and theory for brittle materials and conclude that a theoretical calculation of abrasion is not possible yet. Instead, we use fault-gouge production data to estimate a likely upper bound to abrasion rates, and conclude that sufficient erosion to maintain a steady deforminglayer thickness is difficult to achieve, and will only be possible if the substrate is very soft and if there is a moderate rate of slip at the base of the deforming layer. Slow abrasion, which can leave a geologic signature, is possible under most deforming layers that are deforming at the sediment/bedrock interface.
\end{abstract}

\section{INTRODUCTION}

Some glaciers move, or are inferred to move, significantly by deformation of subglacial sediments (Boulton 1979; Alley and others, 1987; Alley, 1991; Humphrey and others, 1993; Blake and others, 1994; Iverson and others, 1994). The generality of this motion is unknown, but it is important to understand the physics of soft-bed systems not only for application to these specific glaciers, but also as an end member in the continuum of soft to hard beds that likely exists in Nature. In this paper, we explore the potential for erosion by deforming subglacial sediments, a topic that modellers have neglected.

Any physical model of a soft bed should comprise at least) a statement of force balance, a constitutive relation, and a statement of continuity of soft-bed material. The latter motivates studies of sub-sediment erosion. Consider a subglacial layer of sediment (Fig. 1), deforming over a thickness $T$, with an average velocity down-flow $(x$ direction) of $\bar{u}$. If the flow is planar, and the sediment porosity does not change, then continuity requires that

$$
\frac{\partial T}{\partial t}=\dot{S}-\frac{\partial T \bar{u}}{\partial x}
$$

where $\dot{S}$ is the rate of addition of sediment volume to the layer (per unit horizontal area). It is important to know all the terms in Equation (1) because the component of ice velocity due to subglacial shearing is a strong function of $T$ (Alley, 1989); models of soft-bed glacier response need to calculate accurately the evolution of the deforming thickness. Also note that a steady-state softbed system requires a balance between $\dot{S}$ and the flux divergence. It is interesting to know whether this balance is likely in Nature.

In the accumulation zones of glaciers with most of the ice motion due to subglacial shearing, we expect the flux divergence term in Equation (1) to be positive generally, because glacier speed increases down-flow. Also, for the particular case of Ice Stream B, speed increases downflow, possibly due to changes in bed lubrication (Alley and others, 1989). In these cases, a steady state requires a positive $\dot{S}$. If the flux divergence is not balanced by sufficient addition of sediment, the deforming layer will thin and the ice velocity will decline.

A positive $\dot{S}$ may arise in several ways. Melting basal ice may release entrained sediment. If the deforming sediment is only the top of a large reservoir of unconsolidated sediment as when a glacier overrides a

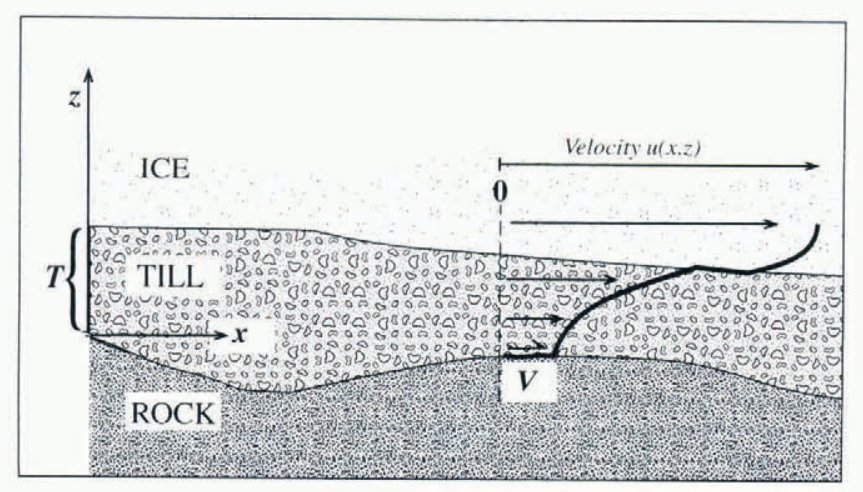

Fig. 1. Situation sketch for Equation (1). A subglacial layer of sediment is deforming through a thickness $T$ and slipping over the substrate at speed $V$. 
sediment-filled lake basin), then mobilization of new sediment at the base of the deforming layer will contribute new volume. If the deforming sediment overlies bedrock, then erosion of this bedrock by the deforming sediment above will also add volume to the deforming layer. The second of these mechanisms will, in time, give way to the third as the reservoir is depleted. The first may be very important.

Observations of striations and flattened boulders in or under deformed glacial deposits provide a second motivation for studies of sub-sediment erosion (MacClintock and Dreimanis, 1964; Clark, 1991). We would like to know if there can be enough erosion under a deforming bed to leave such a signature.

Calculations of erosion by deforming sediment are confounded by the clastic nature of sediment, which results in uncertainty as to how forces are distributed among clasts of differing size and mineralogy, by uncertainties in bulk-deformation properties and by the complex nature of brittle fracture in the abrasion process. We review the tribology literature to illuminate these difficulties. We will not present a rigorous method for calculating erosion rates, but instead we use data on faultgouge production to estimate an upper limit to typical erosion rates. Throughout the paper, we will use the word "till" as synonymous with "subglacial sediment"; till is shorter.

\section{A SIMPLE ABRASION MODEL}

The rate of erosion (thickness per time) due to $N$ identical abrading particles per area of substrate is often written as a simple function of the particle-bed contact force $(F)$, the speed of the particles over the bed $(V)$, and the hardness of the bed $(H)$ :

$$
\dot{S}=\frac{k}{H} N V F \text {. }
$$

Extensive empirical data and simple theoretical models for abrasion of metals support this relation (Hutchings, 1992b; Bayer, 1994), and Boulton (1979) and Hallet (1979) used this relation for modelling abrasion rates under ice.

The hardness $H$ is usually taken to be the indentation hardness which is approximately three times the compressive strength (Brace, 1960). Empirically, for abrasion to be significant, the abrasive must be at least slightly harder than the substrate (Hutchings, 1992b). Substantial abrasion at rock-rock contacts can occur even if the bulk hardness of both rocks is similar, because the hardness varies spatially on a small scale, allowing hard asperities of one rock to contact relatively soft parts of the opposing rock in places. Published data for rocks support the simple inverse relation $\dot{S} \propto H^{-1}$ in an approximate fashion (e.g. Fig. 2; Boulton, 1979; Szymanski and Szymanski, 1989) for a variety of abrasives. The relation is much better for single minerals (e.g. Moore, 1978). Analogy to concretes (Liu, 1981) indicates that for diamictites, such as conglomerate and breccia, the hardness of the coarse clasts is as important a measure of abrasion resistance as bulk rock strength.

At the base of a deforming till, there are many particles of different sizes contacting the bed. Each

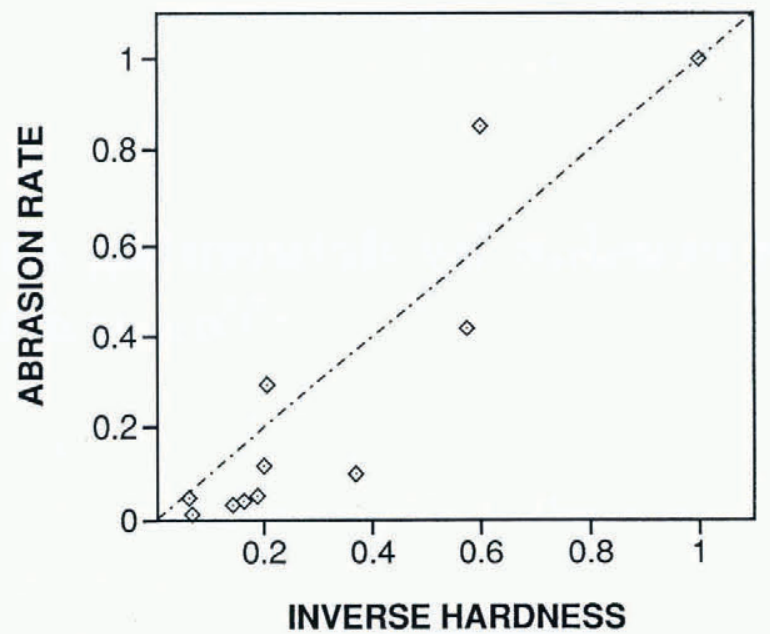

Fig. 2. Abrasion rale as a function of $H^{-1}$, for granite, sandstones, limestone, marble, slate, greenstone, quartzite, hematite, jasper and shale, being abraded by silicon carbide grit. We have normalized the values so that the slope should be one if the proportionality holds. The numbers are therefore non-dimensional, but data units are inverse stress and thickness per time. Data from Avery (1961) and the U.S. Bureau of Mines Report of Investigation 3891, August 1946. We have converted Avery's mass-wear rate to a thickness-wear rate using the densily values given in the original data where possible.

particle erodes a volume $k F V H^{-1}$ per unit time. The contact force of the $i$ th particle is proportional to the effective normal stress, $\sigma$, and an effective area, $\alpha_{i}$, which is not generally known because it depends on the distribution of forces in the granular skeleton in addition to particle geometry. The erosion rate thickness per time) of the bed is therefore

$$
\dot{S}=\left(\sum_{i} \alpha_{i}\right)^{-1} \frac{k}{H} \sum_{i} \sigma V_{i} \alpha_{i}=\frac{k \sigma V}{H}
$$

if all load-bearing particles are sliding over the bed at the same speed. This relation is appealing for its simplicity, in particular because the nature of partitioning of the load between different-sized particles does not matter.

The dimensionless coefficient $k$ depends on the geometry of the abrading system. Abrasion by rubbing of two surfaces in direct contact (two-body abrasion) has a $k$ value an order of magnitude higher than abrasion by loose particles trapped between two moving bodies (three-body abrasion), because in the latter case the particles are free to roll and are only sliding and abrading during a fraction of their motion (Rabinowicz and others, 1961; Larsen-Basse, 1981). Limited experiments with thick columns of abrasives, a reasonable analog for a sediment layer, show abrasion rates comparable to those for single-layer threebody abrasion (Misra and Finnie, 1980, 1981a). Abrasion under a deforming till layer is a form of three-body abrasion because the abrasive particles are free to roll. Thus, results of three-body abrasion experiments are informative, as long as the slip speed $V$ is taken to be the speed of those abrading particles in contact with the substrate, rather than the speed of basal ice at the top of the till layer. Two-body experiments can be used to place an upper limit on three-body abrasion rates. 
Typical three-body $k$ values for metals are 0.0005 0.005 Hutchings, 1992b, p. 200). Hallet found a twobody value of approximately 0.01 in a single experiment with limestone (from Hallet (1979), using $H=10^{8} \mathrm{~Pa}$ for limestone; note that Hallet's $\alpha$ is our $k H^{-1}$, and his $D$ is our $N V$ ), suggesting a three-body value of $k=0.001$, which is a similar value to that for metals. Equation (3) tells us what till-sliding speed is necessary for a given rate of abrasion. Taking $k=0.001$, a till-sliding speed of order $10-1000 \mathrm{ma}^{1}$ is needed to produce $1 \mathrm{~mm} \mathrm{a}^{-1}$ of erosion for soft rocks (chalk; weakly lithified sediments) to hard rocks (granites, limestones, quartzites), given $\sigma=10^{5} \mathrm{~Pa}$ typical rock-hardness values are from Stacey and Page (1986)). Thus, this simple model suggests that subsediment erosion may be significant for soft rocks. Tillsliding is discussed more below.

\section{A MORE REALISTIC ABRASION MODEL}

We now take a more realistic view of the abrasion process and include several factors that can change this first estimate of abrasion rate by orders of magnitude. We are compelled to reintroduce the clastic nature of till.

Equation (3) predicts that abrasion rates do not depend on abrasive-particle size. Yet there are extensive data showing that abrasion rates decrease as size of abrading particles decreases, for a variety of materials, including ductile metals (Misra and Finnie, 1981b), cermets (Larsen-Basse, 1981) and ceramics (Moore and King, 1980; Buckley and Miyoshi, 1984). Most plots of abrasion rate vs particle size are monotonically increasing, and convex up, so that particle size has a large effect for small particles (two or more orders of magnitude for ceramics, between abrasive-particle sizes of 2 and $15 \mu \mathrm{m}$ ), but a minor effect for large particles (larger than about $100 \mu \mathrm{m})$. Given the diversity of materials for which this is true, it is almost certainly true for rocks as well. Experience making rock thin sections provides anecdotal support for this; coarser grits thin a sample faster than fine grits. Very fine grits create a polish, and remove mass only very slowly (e.g. Larsen-Basse, 1994). An empirical description of this hardness -size effect requires at least two adjustable parameters, one describing the magnitude and the other its scaling with volume. Our example of such a relation is

$$
H=H_{0}(R+\chi E)(R+\chi)^{-1}
$$

where $R$ is the abrading particle's radius, $H_{0}$ is the hardness for large particles and large volumes of substrate, $E$ is the maximum enhancement, and $\chi$ is the value of $R$ for which the hardness is exactly half-way between its extremes. If these constants are empirically determined, they will incorporate changes in relative hardness of abrader and substrate due to changes in scaling of the material volume of substrate and size of abrasive.

There are at least three reasons for this size-abrasionrate effect. Two of these invoke a dependence of material hardness on specimen size, and require that the volume of substrate affected by an abrader scales with the size of the abrader. The first is that the ductile-yield strength of materials increases as volume of the material decreases (Misra and Finnie, 1981b; Hutchings, 1992b). This has been measured for ductile materials and for brittle materials deforming plastically at low loads (e.g. Gane and Cox, 1970). Secondly, for brittle materials, as the volume of material decreases it is less likely to contain a significant flaw that can grow into a crack Lawn and Wilshaw, 1975). The third cause of the size-abrasion-rate effect is the non-linear nature of brittle fracture.

The brittleness of rocks has important implications for the abrasion process. Equation(2) applies well for ductile materials like metals. But rocks are comparatively brittle, with fracture toughnesses one to two orders of magnitude smaller than those for engineering metals. For brittle materials like rocks and ceramics, several theoretical abrasion relations have been proposed (Evans and Wilshaw, 1976; Almond, 1986), none of which are supported by empirical data (Moore and King, 1980; Ajayi and Ludema, 1988) except in a very general fashion. These relations and empirical relations for brittle solids all describe the volumetric abrasion rate for a single abrading particle as

$$
\dot{S}=\frac{k_{\mathrm{B}} V F^{m}}{K_{\mathrm{lc}}^{n} H^{\nu}}
$$

where $k_{\mathrm{B}}, m, n$, and $\nu$ are constants. The abrasion rate increases with the brittleness $\left(K_{\mathrm{Ic}}\right.$ is the fracture toughness, which is proportional to the inverse of brittleness), and increases in a non-linear manner with the force. The constants $n$ and $\nu$ are of order unity. Theoretical values for $m$ are $1-1.5$ and empirical values for ceramics and brittle composites range from 0.9 to over 3 , with a mean of $\approx 1.3$ (Evans and Wilshaw, 1976; Moore and King, 1980; Libsch and others, 1986). Limited data from fault-gouge experiments show $m$ values for rocks ranging from about 0.7 to 2.3 (Nagahama and Nakamura, 1994), but the gouge grain-size and fractional area of two-body contact are not controlled in these experiments. Because of this non-linearity, abrasion-rate calculations for rock require knowing how the weight of overburden is partitioned among the clasts at the bed, in contrast to Equation (3). The non-linearity also introduces a size effect. Consider a homogeneous till of spherical particles of radius $R$. Each particle touching the bed supports a load $F=\varepsilon \sigma R^{2}$, where $\varepsilon$ is a geometric factor of order unity. The erosion rate (thickness per time) due to a layer of these particles the number of abrasive particles per area of bed is $\left.1 /\left(\varepsilon R^{2}\right)\right)$ is

$$
\dot{S}=\frac{k_{\mathrm{B}} V \varepsilon^{m-1} \sigma^{m} R^{2(m-1)}}{K_{\mathrm{Ic}}^{n} H^{\nu}}
$$

which shows a monotonic increase with particle size for $m>1$. Also, if $m>1$, the abrasion rate due to a till comprising different grain-sizes will depend on whether the fine particles form a layer between coarse particles and the bed, protecting the bed by distributing the force, or are displaced by the motion of larger particles or pore water.

At the base of any till there are probably both brittle and plastic contacts. Above a certain load, particle size and slip speed, brittle abrasion will dominate and 
Equation (6) will be more appropriate than Equation (2) (e.g. Hutchings, 1992a). We suspect that surface roughness will locally result in high stresses and brittle fracture. The transition cannot be calculated theoretically yet (cf. Hutchings, 1992a; Moore and King, 1980).

Another factor that can significantly affect abrasion rates is the relative hardness of the abrading particle and the substrate. Abrasive particles that are at least slightly harder than the substrate must be present for rapid abrasion to occur (Hutchings, 1992b). As abrasive hardness increases above this level, empirical data show a marked increase of abrasion rate for ceramics but a relatively minor increase for metals (Moore, 1978; Bayer, 1994). We can account for this by introducing a coefficient $H^{*}$ to Equations (5) and (3):

$$
H^{*}=\left(H_{\mathrm{a}} H^{-1}\right)^{\gamma}
$$

where $\gamma$ is a constant, $H_{\mathrm{a}}$ is hardness of the abrasive, and $H$ is hardness of the substrate (both are functions of size). One data compilation shows $\gamma \approx 2$ for ceramics (Moore, 1978). A linear regression on a $\log -\log$ plot of the data in Figure 2 gives a slope of 1.4 , suggesting $\gamma \approx 0.4$ for these rocks if $\nu=1$. Hard abrasive particles in tills quartz particles and granite fragments) will be more effective abraders than soft particles (calcite or especially clays) potentially by orders of magnitude, as one may expect intuitively.

Finally, we can write our "more realistic" bedabrasion equation (thickness eroded per time) by combining Equations (4), (5) and (7), partitioning the overburden so $F_{i}=\sigma \alpha_{i}$ for the $i$ th particle, summing over all particles and dividing by the bed area:

$$
\dot{S}=\left[\sum_{i} \alpha_{i}\right]^{-1} \sum_{i} \frac{k_{\mathrm{B}} H_{i}^{*} V_{i} \sigma \propto_{i}^{m}\left(R_{i}+\chi\right)^{\nu}}{K_{\mathrm{Ic}}^{n} H_{0}^{\nu}\left(R_{i}+E \chi\right)^{\nu}}
$$

where the values of $m, n$ and $\nu$ can change at transitions between dominantly plastic and brittle wear.

\section{A FIRST CONCLUSION: ARE WE LEARNING ANYTHING?}

At this point we have to admit our inability to calculate abrasion rates based on this theory. Equation (8) contains an unfortunate array of unknown parameters that can make at least an order of magnitude difference to the abrasion rate: $m, \gamma, \chi, E$, and $k_{\mathrm{B}}$. For an inhomogeneous till, we also have to know the distribution of $\alpha_{i}$ and $V_{i}$ values. Given the considerable range for these parameters in ceramics and metals, we propose that empirical studies with rocks are essential for substantial progress. We hope the preceding ideas may provide a framework for such experiments.

Despite this dismal picture, we can state several conclusions.

1. There is probably no single abrasion law that applies to all rocks.

2. Fine particles probably do less abrasion than coarse particles. A homogeneous clay till ( $1 \mu \mathrm{m}$ size) probably erodes slower than a sand/coarse-silt till by at least an order of magnitude.
3. In a till with particles of varying mineralogy/lithology, the hard particles will be the most effective abrasives (obvious).

4. Empirical data show that the dependence of $\dot{S}$ on fracture toughness, substrate hardness and relative hardness of abrasive and substrate combine to make $\dot{S} \propto H^{-1}$, approximately (Fig. 2).

\section{AN APPEAL TO FAULT-GOUGE DATA}

We now appeal to observations of natural and synthetic fault gouge, to estimate absolute values for rates of till regeneration, given $V$. Let us describe erosion using the simplest relation (Equation (3)), with the understanding that the coefficient $k$ takes whatever value necessary to make the equality true; $k$ may be a function of all the variables in Equation (8). If all variables are timeinvariant, then integration of $\dot{S}$ and $V$ through time gives the thickness and displacement, respectively. The ratio of thickness generated to displacement $\theta / d$ is $k \sigma H^{-1} \equiv$ $\Psi H^{-1}$. To facilitate glaciologists' use of fault-gouge measurements from diverse stress conditions, with diverse degrees of linearity, we here define the value $\Psi$ as $k \sigma$ for $\sigma=0.5$ bar $\left(1 \mathrm{bar}=10^{5} \mathrm{~Pa}\right)$. For values of $\sigma$ close to 0.5 bar, as we expect at the base of deforming tills, one can scale the erosion rate to $\Psi \sigma / 0.5$ for $\sigma$ in bars.

Fortunately, some data exist for rocks showing $\theta / d$ for synthetic faults. In Table 1 we give $\Psi$ values from these experiments for various rock types, extrapolated to a normal stress of 0.5 bar. We have used typical values for compressive strengths to make this calculation (Stacey and Page, 1986). If these are incorrect, the values of $\Psi$ will change, but not the ratio $\Psi / H$, so our conclusions are not affected. Natural faults have a $\theta / d$ ratio of approximately 0.01 (Scholz, 1987). We include this value for comparison, though the stress during gouge formation and the functional dependence of gouge production on stress are both highly variable and unknown.

Fault-gouge production data are relevant to the erosion problem because they show the production of wear material during slip at rock-rock contacts. The gouge is probably mostly produced in two-body contact where asperities of one sample stick through the accumulating gouge to contact the other sample. Recall that two-body wear rates are at least an order of magnitude higher than three-body wear rates. We do not introduce a correction for this, however, because the fractional area over which the contact occurs is likely an order of magnitude or more less than the total area of the sample surface. One cannot use these experiments to estimate three-body wear rates directly, because the displacement between the gouge layer and the rock-sample surfaces is not known. In the Appendix we note several cautions before applying these data to estimates of erosion rates.

Estimated $\Psi$ values vary over four orders of magnitude, which is not surprising given the many variables in a realistic abrasion relation, and the experiments' variability. The highest $\Psi$ value from a laboratory experiment with the stress known is $\Psi \approx 340$ (Table 1). The next highest $\Psi$ value, and the highest $\Psi$ value measured at a 
Table 1. Estimates of faull-gouge production-rate coefficients for rocks at a stress of 0.5 bar. We extrapolate to 0.5 bar using equations of the form $\theta / d=g \sigma^{m}$, where $G$ and $m$ are constants delermined by regression of experimental data. Some experiments have data at only one value of $\sigma$. For these we assume an $m$ value, as shown, and use $\theta / d=\left.(\theta / d)\right|_{\sigma}(0.05 / \sigma)^{m}$ to get $\Psi(\sigma$ in $M P a)$. The first len values are results from laboratory experiments. The last is an estimate based on natural faults, which have a thickness/displacement ratio of $\approx 0.01$

Source

Lithology

H

$\mathrm{MPa}$

$m$

$\Psi \approx \Theta H d^{-1}$
$\mathrm{~Pa}$

$k$

d

$\mathrm{m}$

$\begin{array}{lrcccc}\text { Sandstone } & 65^{\mathrm{E}} & 1.00^{\mathrm{E}} & 340 & 6.8 \mathrm{E}-3 & 0.01 \\ \text { Marble } & 100^{\wedge} & \text { N.E. } & 11 & 2.2 \mathrm{E}-4 & \approx 5000 \\ \text { Limestone } & 100^{\wedge} & \text { N.E. } & 8.9 & 1.8 \mathrm{E}-4 & \approx 5000 \\ \text { Dolomite } & 100^{\wedge} & 1.5^{\wedge} & 6.0 & 1.2 \mathrm{E}-4 & 0.011 \\ \text { Talc } & 5^{\wedge} & \text { N.E. } & 0.99 & 2.0 \mathrm{E}-5 & \approx 5000 \\ \text { Gypsum } & 10^{\wedge} & \text { N.E. } & 0.56 & 1.1 \mathrm{E}-5 & \approx 5000 \\ \text { Granite } & 200^{\wedge} & 2^{\wedge} . & 0.34 & 6.8 \mathrm{E}-6 & 0.018 \\ \text { Granite } & 200^{\wedge} & 2^{\wedge}{ }^{\wedge} & 0.068 & 1.4 \mathrm{E}-6 & 0.38 \\ \text { Sandstone } & 100^{\wedge} & 2.22^{\mathrm{E}} & 0.028 & 5.6 \mathrm{E}-7 & 0.008 \\ \text { Granite } & 150^{\mathrm{E}} & 2.38^{\mathrm{E}} & 0.023 & 4.6 \mathrm{E}-7 & 0.01\end{array}$

Yoshioka $(1985)^{8}$

Morohashi and others $(1973)^{1}$

Morohashi and others (1973)

Power and others $(1988)^{2}$

Morohashi and others (1973)

Morohashi and others (1973)

Power and others $(1988)^{3}$

Blanpied and others (1987)

Teufel $(1981)^{8}$

Yoshioka $(1985)^{8}$

\begin{tabular}{|c|c|c|c|c|c|}
\hline Sandstone & $65^{\mathrm{E}}$ & $1.00^{\mathrm{E}}$ & 340 & $6.8 \mathrm{E}-3$ & 0.01 \\
\hline Marble & $100^{-1}$ & N.E. & 11 & $2.2 \mathrm{E}-4$ & $\approx 5000$ \\
\hline Limestone & $100^{A}$ & N.E. & 8.9 & $1.8 \mathrm{E}-4$ & $\approx 5000$ \\
\hline Dolomite & $100^{4}$ & $1.5^{\wedge 5}$ & 6.0 & $1.2 \mathrm{E}-4$ & 0.011 \\
\hline Talc & $5^{-1}$ & N.E. & 0.99 & $2.0 \mathrm{E}-5$ & $\approx 5000$ \\
\hline Gypsum & $10^{.1}$ & N.E. & 0.56 & $1.1 \mathrm{E}-5$ & $\approx 5000$ \\
\hline Granite & $200^{A}$ & $2^{\wedge 6}$ & 0.34 & $6.8 \mathrm{E}-6$ & 0.018 \\
\hline Granite & $200^{-1}$ & $2^{46}$ & 0.068 & $1.4 \mathrm{E}-6$ & 0.38 \\
\hline Sandstone & $100^{A}$ & $2.22^{\mathrm{F}}$ & 0.028 & $5.6 \mathrm{E}-7$ & 0.008 \\
\hline Granite & $150^{\mathrm{E}}$ & $2.38^{\mathrm{E}}$ & 0.023 & $4.6 \mathrm{E}-7$ & 0.01 \\
\hline
\end{tabular}

\section{Scholz (1987)}

\section{Various}

$100^{\Lambda}$

$1.5^{\wedge} 7$

$32^{4}$

$6.2 \mathrm{E}-5 \quad$ Various

\footnotetext{
A The value was assumed.

E. The value was experimentally determined.

N.E. No extrapolation to 0.5 bar was necessary.

1 Reported in Nagahama and Nakamura (1994).

2 Attributed to Weeks and Tullis (1985) in Power and others' Table 1 .

3 Attributed to Tullis and Weeks (1986) in Power and others Table 1 .

4 Assumes stress of $50 \mathrm{MPa}$ during gouge formation, a typical crustal value,

$5 m=1.5$ used for dolomite by analogy with Morohashi and others
}

\begin{abstract}
data for limestone.
5 $m=2$ used for granite by analogy with Yoshioka's data for granite.

$m=1.5$ is an approximate average of measured values for different rock types based on Morohashi and others', Tcufel's and Yoshioka's data).

8 Regression equation given by Nagahama and Nakamura 1994), and confirmed by us. Nagahama and Nakamura seem to have switched their regression equations for granite and sandstone in their ligure 4.
\end{abstract}

\section{HOW SIGNIFICANT IS SIGNIFICANT?}

From the standpoint of till continuity, we consider erosion to be "significant" if it is sufficiently large to maintain the till thickness Equation (1)) by balancing the till-flux divergence. To show how this divergence depends approximately on the physical setting and character of the till, we write the speed of the till as $u=V$ $+\left(u_{\mathrm{t}}-V\right)(z / T)^{a}$, where $u_{\mathrm{t}}$ is the speed at the top of the till (and represents the total contribution of the till to the ice motion), $a$ is a constant describing the nonlinearity of the till deformation, and $z=0$ at the base of the till and increases to $T$ at the top (Fig. 1). Further, we write $V$ as a fraction $f$ of the total speed $V \equiv f u_{\mathrm{t}}$. Finally, if we convert rock thickness to till thickness using the till porosity, $\phi$, and if $a$ and $f$ do not change with $x$, then the erosion rate needed to balance the flux divergence is

$$
\dot{S}_{\mathrm{b}}=(1-\phi) \frac{(1+a f)}{(1+a)} \frac{\partial u_{\mathrm{t}} T}{\partial x}=(1-\phi) \frac{(1+a f) T}{(1+a)} \frac{\partial u_{\mathrm{t}}}{\partial x}
$$

harder than granite. However, a quartz particle or hard lithic fragment may be two orders of magnitude or more harder than a weakly lithified marine sediment, which could enhance the abrasion rate considerably for an individual particle Equation (7)). If the concentration of hard particles is high, this can significantly enhance the total abrasion rate. 
proportion of total speed due to basal-till slip increases, the effect of the non-linearity becomes less important. Typical longitudinal strain rates in glaciers are of order $\dot{b} T_{\mathrm{i}}^{-1}$, where $\dot{b}$ is accumulation rate and $T_{\mathrm{i}}$ is ice thickness. If most of the glacier's motion is due to subglacial shearing, then $\partial u_{\mathrm{t}} / \partial x \approx \dot{b} T_{\mathrm{i}}^{-1}$. Using typical ice-stream values of $\dot{b}=0.1 \mathrm{~m} \mathrm{a}^{-1}, T_{\mathrm{i}}=1000 \mathrm{~m}, T=2 \mathrm{~m}$, and using $H^{*}=1$, gives a necessary erosion rate of $\dot{S}_{\mathrm{b}} \approx 10^{4} \mathrm{ma}^{-1}$ for $f=0$ and $a=1$. This is our reason for using $10^{-4} \mathrm{~m} \mathrm{a}^{1}$ as the minimum $\dot{S}$ that is "significant". In general the tillslip speed necessary for steady state is (Fig. 3)

$$
V_{\mathrm{b}}=\frac{H \sigma *}{H^{*} \Psi\left(\sigma_{0}+\rho_{\mathrm{b}} g T\right)}(1-\phi)\left(\frac{1+a f}{1+a}\right) \frac{\partial\left(u_{\mathrm{t}} T\right)}{\partial x}
$$

where $\sigma *$ is the constant reference stress used in the definition of $\Psi$, and is equal to $0.5 \mathrm{bar}, \sigma_{0}$ is the effective stress at the ice/till interface, $\rho_{\mathrm{b}}$ is the buoyant density of the till (bulk density minus water density), $g$ is gravity, and the vertical normal stress balances the weight of overburden. For our typical till, $V_{\mathrm{b}}$ is $20 \mathrm{ma}^{-1}$ to $2 \mathrm{~km} \mathrm{a}^{-1}$ for soft to hard rocks. In Nature there are probably situations in which steady state requires vastly greater or smaller erosion rates.

If the abrasion rate under a deforming layer is low, so the flux divergence is not balanced, the layer will thin. The flux divergence will decrease coincidentally and a steady state may be established (Fig. 3). For the maximum plausible erosion rate $(\Psi=10)$, and linear rheology, the till thickness at steady state is several meters for very soft rocks, but several centimeters for hard rocks. A very thin till will not produce rapid glacier motion unless the water pressure is very close to overburden, or the rheology of the till is highly non-linear. Both are possible, in which case our assessment of "significance" is too conservative. Similarly, if there is sliding or ploughing at the ice/till interface, the down-flow velocity gradient in the till could be less than that of the overlying ice.

Of course much smaller abrasion rates than tenths of millimeters per year can produce identifiable features that are geologically significant. Abrasion at a low rate can

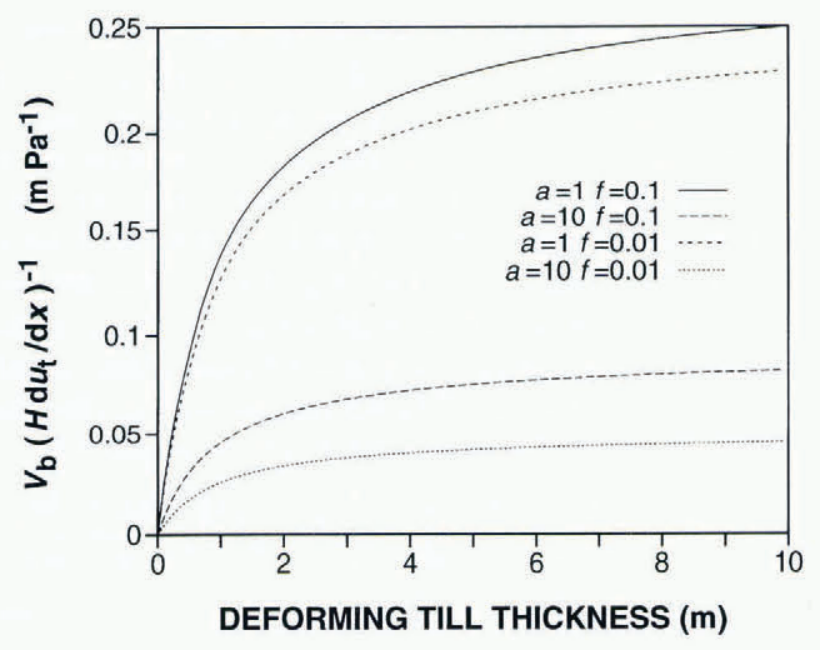

Fig. 3. Slip velocity necessary to balance till-flux divergence, as a function of till thickness, non-linearity (a), and fraction of total till speed due to slip at the base of the till $(f)$. The erosion rate is normalized to the ice longitudinal strain rate and the material hardness. polish a rock surface. An abrasion rate of $10^{-6} \mathrm{~m} \mathrm{a}^{-1}$ will erode several millimeters of rock in several thousand years, which is sufficient to smooth and striate a surface. The preservation of striations will depend on the frequency of striating events relative to the polishing rate. The flattened boulders discussed by Clark (1991) were supposedly flattened in less than a millennium, suggesting a higher abrasion rate than the $10^{6} \mathrm{ma}^{-1}$ we infer as a high value for hard rocks. A higher abrasion rate might be achieved by high till-sliding speeds around the boulder and enhanced normal stress on the boulder surface. Alternatively, it may require direct abrasion by clast-bearing ice, or unusually weak rocks.

\section{TILL-SLIDING: THE NEXT BUGABOO. NEED IT BE FAULT-PLANE-STYLE?}

The till-sliding speed $V$ is a crucial parameter in all of these abrasion relations. The most favorable physical situation for abrasion is that the base of the till acts as a fault plane, so all particles are sliding over the substrate at $V$. A less favorable situation, but one that is perhaps more common in Nature, is that relatively large clasts touching the bed, or separated from the bed by a single layer of particles, are propelled forward by faster moving till above the bed, because there is a shear gradient in till speed (Alley and others, 1987). We are aware of only two observations that suggest fault-plane-style till-sliding is occurring, or that there is an enhanced shear strain rate near a solid boundary. First, Boulton (1979, fig. 7) observed a marker embedded in deforming till that had scooted across the top of a boulder with an apparent "sliding" speed of $\approx 4 \mathrm{ma}^{-1}$. Secondly, and more compellingly, Boulton observed slickensided sub-horizontal joint planes in the slowly deforming, dense, lower till layer beneath Breidamerkurjökull (Boulton and Hindmarsh, 1987).

The contact zone between till and substrate is similar to any horizontal plane within the till, but with a different smoothness and greater rigidity on one side. Analogy with rheologic relations for till (Alley, 1989; Kamb, 1991) suggests a till-sliding relationship should have the form

$$
V=\delta \dot{\varepsilon}_{x z}=\delta \frac{(\tau-\mu \sigma)^{\bar{a}}}{\eta}
$$

where $\dot{\varepsilon}_{x z}$ is the shear strain rate, $\eta$ is effective till viscosity (dimensions of $s \mathrm{~Pa}^{\bar{a}}$ ), $\bar{a}$ is a number describing the degree of linearity of the constitutive relation, $\mu$ is a friction coefficient, and $\delta$ is a length scale that increases with bed smoothness. Within a till, $\delta$ is a characteristic particle radius. For a shear strain rate of $10 \mathrm{a}^{-1}$, and $\delta=10^{4} \mathrm{~m}, V$ is $1 \mathrm{~mm} \mathrm{a}^{-1}$, which suggests that till-sliding speeds will be very low if the roughness of the substrate is comparable to the roughness of planes within the till. Substrates can be much smoother than this, and hence larger slip speeds are a theoretical possibility. Equation (11) states that shear stress in the plane of the bed in excess of the tangential friction can drive sliding, a situation analogous to that for sliding of dirty ice (Hallet, 1981).

Suppose there is no fault-like sliding motion at the base of the till. In this case, relatively large clasts 
contacting the bed may cause erosion if they protrude upward into moving till which can drag the clasts forward. Is significant erosion possible in this situation? If the clast acts as part of a skeleton of grains transmitting the overburden to the bed, then the area over which the clast can induce rolling and sliding motion of smaller particles on the bed (so there is three-body abrasion) is approximately $\pi L^{2}$, where $L$ is the geometrically determined closest approach distance of a matrix particle to the contact point of a large clast and a flat plane on which it rests. For spherical particles resting on a flat plane, this area is approximately $4 \pi R r$, where $R$ is the clast radius, and $r$ is the matrix particle radius. Assuming the linear relation (Equation (2)) applies, the abrasion rate per unit area of bed will be $S \approx 4 k H^{-1} \sigma r C_{R} \dot{\varepsilon}_{x z}$ where $C_{R}$ is the concentration of clasts of radius $R, \dot{\varepsilon}_{x z}$ is the shear strain rate in the till, and we assume the clast moves forward with speed $\dot{\varepsilon}_{x z} R$. Using a high three-body $k$ value of 0.001 (Table 1), a soft-rock $H=10^{6} \mathrm{~Pa}$, $C_{R}=0.1$, a high $\sigma=10^{5} \mathrm{~Pa}$, and $r=10^{-4} \mathrm{~m}$ (fine sand) shows that, even in this favorable case, an abrasion rate of $10^{-4} \mathrm{~m} \mathrm{a}^{-1}$ requires a shear strain rate of order $10^{4} \mathrm{a}^{-1}$. This is very high, and seems prohibitive. Very low abrasion rates are possible, though.

Now suppose the till matrix is fluidized sufficiently so that it does not support the weight of the clasts, as envisioned by Clark (1991). Then the contact force is the buoyant weight of the clast, $F \approx 4 g R^{3} \rho_{\mathrm{b}}$. $V$ for this clast will be, at most, approximately $R \dot{\varepsilon}_{x z}$, because friction against the bed will slow it in the manner described by Hallet (1979) for particles in basal ice. Using Equation (2) with $N=C_{R} /\left(\pi R^{2}\right)$ gives

$$
\dot{S} \approx k H^{-1} C_{R} g \rho_{\mathrm{b}} R^{2} \dot{\varepsilon}_{x z} .
$$

A high two-body value for $k$ is 0.01 , for which $k / H$ ranges from $10^{-8}$ to $10^{-10}$. Using $\rho_{\mathrm{b}} \approx 10^{3} \mathrm{~kg} \mathrm{~m}^{-3}, C_{R}=0.1$, and a radius of one decimeter, we get $0.01 \mathrm{~mm} \mathrm{a}^{-1}$ erosion for soft rocks $\left(0.0001 \mathrm{~mm} \mathrm{a}^{-1}\right.$ for hard ones) for a high, but possible, shear strain rate of $100 \mathrm{a}^{-1}$. The erosion rate will be larger if there is a strong longitudinal strain rate inducing vertical motion of the till and forcing clasts against the bed (Hallet, 1979). This could be an important effect despite the low viscosity of till, because frictional forces on bodies immersed in deforming till can be large (Iverson and others, 1994). We have otherwise favored abrasion in these calculations, and therefore suggest that no significant erosion can occur without fault-plane-style sliding or greatly enhanced shear strain rate at the till/substrate interface, except possibly in the presence of very soft substrates or locally strong downward motion. However, abrasion at a low rate, which can polish and striate rocks, is again possible.

\section{A SECOND CONCLUSION}

Our interpretation of fault-gouge production data for rocks suggests that till erosion of $10^{-4} \mathrm{ma}^{-1}$ or more is unlikely except under special circumstances. These include the presence of a very weak substrate, high strain rates at the base of a clast-rich till, or high $\left(>100 \mathrm{~m} \mathrm{a}^{-1}\right)$ till-sliding speeds. Weak substrates do exist in Nature, and high strain rates are possible. High tillsliding speeds seem unlikely, however. We do not know how to calculate till-sliding speeds. Without some modest till-sliding (meters per year) or high strain rate near the bed, significant erosion is unlikely. A till that is not deforming near its base will shield the bed from erosion. We wish to emphasize that these conclusions are not rigorous, and that though they may be true in general there can always be special circumstances in Nature where they are violated. We also emphasize that although abrasion rates of tenths of millimeters or more per year are difficult to achieve by our reasoning, we also have found no theoretical barriers to low abrasion rates under most tills that are deforming at the till/substrate interface, the exception being a till that is devoid of clasts and has no fault-style sliding at its base. Low abrasion rates can be sufficient to leave a geologic signature and even, in some circumstances, to balance the till-flux divergence as when the till is very thin). We recommend empirical studies of abrasion to test our conclusions.

Finally, returning to the larger picture of till continuity, we suggest that, in general, deforming bed systems will last only as long as their reservoir of unconsolidated sediments is undepleted, unless the substrate is soft, or the deforming layer is resupplied by melt of dirty basal ice. Till-thinning rates of order $10^{-4} \mathrm{~m}$ $\mathrm{a}^{-1}$ can easily be balanced by melt of basal ice with modest debris content. However, a strong melt rate maintained along a flowline may lead to exhaustion of debris-bearing ice. Whether unconsolidated material can accumulate and be maintained subglacially will depend strongly on the characteristics of individual glacier systems.

\section{ACKNOWLEDGEMENTS}

This paper is based, in part, on work supported by a U.S. National Science Foundation Graduate Research Fellowship to K.C. We thank B. Hallet and C. Raymond and reviewers $\mathrm{N}$. Iverson and S. Tulaczyk for their helpful criticisms, some of which are not answered here.

\section{REFERENCES}

Ajayi, O. O. and K. C. Ludema. 1988. Surface damage of structural ceramics: implications for wear modeling. Wear, 124 (2), 237-257.

Alley, R. B. 1989. Water-pressure coupling of sliding and bed deformation: II. Velocity-depth profiles. J. Glaciol., 35119 , 119 129.

Alley, R. B. 1991. Deforming-bed origin for southern Laurentide till sheets? f. Glaciol., $37(125), 67-76$.

Alley, R. B., D. D. Blankenship, C. R. Bentley and S. T. Rooney. 1987. Till beneath Ice Stream B. 3. Till deformation: evidence and implications. J. Geophys. Res., 92 B9), 89218929.

Alley, R. B., D. D. Blankenship, S. T. Rooney and C. R. Bentley. 1989. Water-pressure coupling of sliding and bed deformation: III. Application to Ice Stream B, Antarctica. J. Glaciol., 35 119), 130-139.

Almond, E. A. 1986. Indentation phenomena and wear of surfaces and edges. Mal. Sci. Technol., 2 7), 641-646.

Avery, H.S. 1961. Measurement of wear resistance. Wear, 4 6), 427 449.

Bayer, R.G. 1994. Mechanical wear prediction and prevention. New York, Marcel Dekker.

Blake, E. W., U. H. Fischer and G. K. C. Clarke. 1994. Direct measurement of sliding at the glacier bed. $\mathcal{J}$. Glaciol., 40 136), 595-599.

Blanpied, M. L., T. E. Tullis and J. D. Weeks. 1987. Frictional behavior 
of granite at low and high sliding velocities. Geophys. Res. Lell., 14(5), 554557.

Boulton, G.S. 1979. Processes of glacier erosion on different substrata. F. Glaciol., 2389 , $15-38$.

Boulton, G.S. and R. C.A. Hindmarsh. 1987. Sediment deformation beneath glaciers: rheology and geological consequences. J. Geophys. Res., 92 B9), 90599082.

Brace, W. F. 1960. Behavior of rock salt, limestone, and anhydrite during indentation. J. Geophys. Res., 65 6), 1773-1788.

Buckley, D. H. and K. Miyoshi. 1984. Friction and wear of ceramics. Wear, 100, 333-353.

Clark, P. U. 1991. Striated clast pavements: products of deforming subglacial sediment? Geology, 19 (5), $530-533$.

Evans, A. G. and T. R. Wilshaw. 1976. Quasi-static particle damage in brittle solids. I: Observations, analysis and implications. Acta Metall., $24(10), 939-956$.

Gane, N. and J. M. Cox. 1970. The micro-hardness of metals at very low loads. Philos. Mag., 22 179), 881-891.

Hallet, B. 1979. A theoretical model of glacial abrasion. J. Glaciol., 23(89), $39-50$.

Hallet, B. 1981. Glacial abrasion and sliding: their dependence on the debris concentration in basal ice. Ann. Glaciol., 2, 23-28.

Humphrey, N., B. Kamb, M. Fahnestock and H. Engelhardt. 1993. Characteristics of the bed of the lower Columbia Glacier, Alaska. J. Geophys. Res., 98 B1), 837-846.

Hutchings, I. M. 1992a. Ductile brittle transitions and wear maps for the erosion and abrasion of brittle materials. J. Phys. A., 25 (1), 212 221.

Hutchings, I. M. 1992b. Tribology: friction and wear of engineering materials. London, Edward Arnold.

Iverson, N. R., P. Jansson and R. LeB. Hooke. 1994. In-situ measurement of the strength of deforming subglacial till. J. Glaciol., 40 136), $497-503$.

Kamb, W. B. 1991. Rheological nonlinearity and flow instability in the deforming-bed mechanism of ice-stream motion. 7. Geophys. Res., $96(\mathrm{~B} 10), 16,585-16,595$.

Larsen-Basse, J. 1981. Abrasive wear resistance of tungsten carbide composites with iron-nickel binder. In Rhee, S. K., A. W. Buff and K. C. Ludema, eds. Wear of materials. New York, American Society of Mechanical Engineers, 534-538.

Larsen-Basse, J. 1994. Abrasive wear of ceramics. In Jahanmir, S., ed. Friction and wear of ceramics. New York, Marcel Dekker, 99-115.

Lawn, B. R. and R. Wilshaw. 1975. Indentation fracture: principles and applications. J. Maler. Sci., 10 6), 1049-1081.

Libsch, T. A., P. C. Becker and S. K. Rhee. 1986. Dry friction and wear of toughened zirconias and toughened aluminas against steel. Wear, $110(3), 263283$.

Liu, T. C. 1981. Abrasion resistance of concrete. 7. Amer. Concrete Inst,, 78 - $541-350$.

MacClintock, P. and A. Dreimanis. 1964. Reorientation of till fabric by an overriding glacier in the St. Lawrence Valley. Am. J. Sci., 262 (1), $133-142$.

Misra, A. and 1. Finnie. 1980. A classification of three-body abrasive wear and design of a new tester. Wear, 60 1), 111-121.

Misra, A. and I. Finnic. 1981a. An experimental study of three-body abrasive wear. In Rhee, S.K., A.W. Buff and K.C. Ludema, eds. Wear of materials. New York, American Society of Mechanical Engineers, 426431.

Misra, A. and I. Finnie. 1981b. On the size effect in abrasive and erosive wear. Wear, 65 (3), 359-373.

Moore, M. A. 1978. Abrasive wear. Int. J. Mater. Eng. Appl., 1 2), 97-111.

Moore, M. A. and F. S. King. 1980. Abrasive wear of brittle solids. Wear, 60 1$), 123-140$.

Morohashi, S., Y. Sawahata and S. Yashima, 1973. [Effect of operational conditions on the formation of ultrafine powder by a reciprocating friction mill.] J. Soc. Mater. Sci. Jpn, 22, 689-692. [In Japanese with English summary.]

Nagahama, H. and N. Nakamura. 1994. Application of the Pi Theorem to the wear rate of gouge formation in frictional sliding of rocks. Pure Appl. Geophys., 142 (3), 795-808.

Power, W. L., T. E. Tullis and J. D. Weeks. 1988. Roughness and wear during brittle faulting. J. Geophys. Res., 93 B12), 15,268-15,278.

Rabinowicz, E., L. A. Dunn and P. G. Russell. 1961. A study of abrasive wear under three-body conditions. Wear, 4 5 , 345-355.

Scholz, C. H. 1987. Wear and gouge formation in brittle faulting. Geology, $\mathbf{1 5}(6), 493-495$.
Stacey, T. R. and C. H. Page. 1986. Practical handbook for underground rock mechamics. Clausthal-Zellerfeld, Trans Tech Publications. Series on Rock and Soil Mechanics 12.

Szymanski, A. and A. M. Szymanski. 1989. Hardness estimation of minerals, rocks and ceramic materials. Amsterdam, Polish Scientific Publishers and Elsevier. Materials Science Monographs 49.

Teufel, L.W. 1981. Pore volume changes during frictional sliding of simulated faults. Geophys. Monogr. Am. Geophys. Union, 25, $135-145$.

Tullis, T. E. and J. D. Weeks. 1986. Constitutive behavior and stability of frictional sliding of granite. Pure Appl. Geophys., 124 3 ), 383414.

Weeks, J.D. and T.E. Tullis. 1985. Frictional sliding of dolomite: a variation in constitutive behavior. 7. Geophys. Res., 90 B9), 7821-7826.

Yoshioka, N. 1985. Temperature measurement during frictional sliding of rocks. 7. Phys. Earth, 33 4), 295-322.

\section{APPENDIX}

Several cautions should be noted before applying faultgouge production data to estimates of erosion rates. First, some (perhaps most) experiments are not at steady state. They begin with two clean rock surfaces in mutual contact. As gouge develops, the amount of contact between the surfaces decreases until eventually there is no direct contact, and most of the displacement occurs by deformation of the gouge (Power and others, 1988). In some experiments, the displacement rate at the rocksample surfaces at this stage is negligible, so gouge production essentially ceases. Because the fractional area of two-body contact during gouge production is uncertain and variable, we are uncertain how to correct the twobody data to three-body values. This variability contributes to the scatter in $\Psi$ values, and to the uncertainty in our interpretation of them. Our approach is to use a high value for $\Psi$ to strengthen our argument that erosion will be slow.

A second potential problem arising from the nonsteady nature of the experiments is that the displacements reported may include displacement occurring after the production of gouge ceases. This would result in underestimation of $\Psi$ values, and $\Psi$ values should decrease with displacement. In fact, our $\Psi$ values do not decrease with displacement (Table 1). Yoshioka's (1985) data are from an experiment before which he cleaned the fault surfaces of gouge. Teufel's (1981) data actually show an approximately linear increase of gouge thickness with displacement. Morohashi and others' (1973) data have very large displacements, and yet have $\Psi$ values that are similar to those for experiments with much smaller displacements. For Power and others' (1988) data, we have used only the values for the smallest displacements. Thus, we do not consider this transient behavior to be a problem in our data compilation.

A third potential problem is that the stresses in most experiments are several orders of magnitude higher than the effective stress expected at the base of a deforming till, making the extrapolations suspect. The exception is Morohashi and others' data, whose range includes half a bar. Again, because these $\Psi$ values are similar to those with large extrapolations, we suspect the extrapolations are appropriate, at least on average, although the sliding speed in the Morohashi experiments also was high. 